\title{
Ensino da produção de artigo acadêmico: uma abordagem sociorretórica
}

\section{Ana Lúcia Magalhães ${ }^{1}$}

escrita acadêmica competente inclui um conjunto de habilidades e posi-
cionamentos como planejamento, estabelecimento de metas, resolução
de problemas e avaliação criteriosa. O maior desafio dos professores tem sido
motivar os alunos, que tendem a considerar tal tipo de produção escolar como
uma tarefa muito separada da realidade cotidiana de um tecnólogo ${ }^{2}$. Existem
outros problemas como o plágio e a dificuldade de estruturar e desenvolver
escrita mais complexa do que qualquer outra vivenciada anteriormente. Uma
das soluções que pode contribuir para essa questão é o estudo de gêneros
textuais, que fornece ferramentas para o ensino da produção acadêmica,
uma vez que o artigo acadêmico é, em si, um gênero textual.
Há basicamente três perspectivas teóricas para estudar gêneros tex-
tuais: sociossemiótica (Halliday, 1994; e Fairclough, 2001), centrada na
léxico-gramática e contextos sociais; sociodiscursiva (Bakhtin, 2006; e
Maingueneau, 1997), que privilegia o caráter social em prejuízo do es-
trutural; e sociorretórica (Swales, 2004; e Bazerman, 2013), que se ocupa,

1 Doutora em Língua Portuguesa pela PUC-SP, possui graduação em Letras pela Faculdade de Filosofia, Ciências e Letras de Lorena (1974) e mestrado em Língua Portuguesa pela PUC-SP (2001); Membro do Grupo ERA.

2 Os cursos de tecnologia são faculdades com forte componente mercadológico e duração de três anos. A diferença entre o tecnólogo e um bacharel ou licenciado é que a formação do primeiro é mais focada, com disciplinas bastante específicas, enquanto os outros dois são mais generalistas. 
sobretudo, da organização retórica e das soluções comunicativas dos textos. Embora essas correntes não sejam as únicas a tratar dos gêneros comentados, representam aqui o pensamento teórico pertinente.

Este capítulo fundamenta-se ainda em Aristóteles (2003 [230 a.C.]), Meyer (2007), Perelman e Tyteca (1999 [1958]) e Toulmin (2003 [1958]), que esclarecem sobre a Retórica em âmbito profundo, no sentido de não ser possível a elaboração de qualquer texto - e acrescentamos, em particular o artigo acadêmico - sem levar em conta os sujeitos e suas colocações argumentativas, representadas nas estruturas discursivas.

O domínio do entendimento sobre ethos, pathos e logos ligados, respectivamente, a orador, ouvinte/leitor e discurso, assim como a compreensão das estruturas internas do argumento (TOULMIN, 2003) são essenciais na construção do artigo acadêmico, embora possam não aparecer objetivamente nesses textos.

A partir dessas considerações, a proposta deste trabalho é apresentar uma experiência com inclusão da sociorretórica na prática do ensino em escola tecnológica de nível superior, cujos cursos são tipicamente voltados para o mercado e envolvem, muitas vezes, disciplinas da área de exatas. Os alunos esperam desses cursos o desenvolvimento de competência e habilidades próprias e costumam considerar como irrelevantes as matérias que não proporcionam formação específica. No entanto, é esperado de qualquer profissional competência em se comunicar, entendida não apenas como capacidade de troca de informações, mas também o domínio de habilidades argumentativas, sob pena de ter seu progresso dificultado. À medida que o profissional se desenvolve na carreira, as aptidões não técnicas aumentam de importância.

Desse modo, este capítulo toma como base a experiência com estudantes de cursos tecnológicos das Fatecs3 das cidades de Guaratinguetá e Cruzeiro (estado de São Paulo) ao longo de seis anos. Foram, no total, vinte turmas com cerca de quarenta alunos cada, ou seja, uma observação de aproximadamente oitocentos alunos. Evidentemente não se pode dizer que todos apresentaram o mesmo desempenho, até porque os trabalhos são feitos em grupos de três integrantes, o que pode mascarar os resultados, tendo em vista que nem sempre se dá a participação efetiva e completa de cada um dos indivíduos em processos dessa natureza.

3 As Fatecs são escolas tecnológicas de nível superior localizadas no Estado de São Paulo. 
Acrescentamos que é comum graduandos, ao ingressarem no nível superior, apresentarem dificuldade na elaboração dos textos solicitados pelos docentes e tal dificuldade pode se estender por todo o curso caso a habilidade correspondente não seja exercitada, portanto, trata-se de desafio permanente. Observa-se, ainda, um crescimento do ensino de gêneros textuais, principalmente em trabalhos direcionados à docência e à pesquisa da língua escrita. Acreditamos, dessa forma, que o ensino do gênero artigo acadêmico (CASTELLÓ, 2010) exercita todas aquelas capacidades, além de fortalecer a autodisciplina. Além do mais, uma vez que a competência (BRZOVIC, FRASER, LOEWY e VOGT, 2006) dos alunos para escrever com clareza e eficácia afeta o desempenho em todo o currículo, há razões para introduzir esse gênero textual já no primeiro semestre dos cursos superiores, independentemente dos desafios envolvidos.

Para tanto, pretendemos, com este trabalho, responder à seguinte questão de pesquisa: quais as estratégias retóricas estão privilegiadas nos artigos acadêmicos? Tencionamos, como proposição, mostrar que o exercício da escrita de artigo, já a partir do primeiro semestre do nível superior, em quaisquer cursos, auxilia em várias etapas da aprendizagem para além dos aspectos formais do texto e permite alcançar uma análise sociorretórica conforme proposta por Swales (1990), Bazerman (2013) e Bakhtin (2003), que tratam dos gêneros textuais. Ao final mostramos o resultado de uma pesquisa realizada com alunos e professores, sobre a produção de artigo acadêmico.

Carolyn O'Hara, em artigo publicado pela Harvard Business Review (2014), escreveu um conjunto de instruções sobre como melhorar a escrita organizacional. O primeiro conselho diz respeito a pensar antes de escrever, para não confeccionar uma colcha de retalhos de pensamentos avulsos e pouco conectados, o que acontece com relativa frequência, ao menos entre alunos de escolas tecnológicas. A escrita acadêmica é estruturada quase por definição. Outra diretriz dessa autora trata da necessidade de objetividade nesse tipo de texto. Um artigo acadêmico afirma seu objetivo no início e mostra, nessa mesma instância, a questão (ou questões) de pesquisa. O’Hara (2014) também recomenda evitar jargões e, portanto, uma cuidadosa seleção de palavras. A orientação inclui, também, revisão constante do que se escreve e opção por períodos menores, mais diretos. Tais recomendações se aplicam, na íntegra, à prática de produção do artigo acadêmico, que apresenta as mesmas exigências de clareza e objetividade da escrita organizacional. 


\section{Competências}

As habilidades que se deseja desenvolver nos estudantes, e com base nos conceitos da sociorretórica, dizem respeito à organização retórica e capacidade de comunicação, conforme Swales (2004), Bhatia (1993) e Bazerman (2013). A Tabela 1 a seguir, fundamentada em esquema criado por Brzovic et all. (2006), no contexto de ensino de comunicação, mostra algumas competências da escrita acadêmica que, segundo os autores, apuram a capacidade de produzir boa comunicação e estrutura retórica relevante.

Existem duas palavras para competência, em inglês: competency, que designa características comportamentais (difíceis de adquirir, o que torna particularmente importantes as ferramentas eficazes), e competence, que se refere a predicados técnicos e funcionais. As tabelas tratam das competencies.

Tabela 1 - Competências formais

\begin{tabular}{|c|c|c|c|}
\hline $\begin{array}{l}\text { compe- } \\
\text { tência }\end{array}$ & básico & intermediário & avançado \\
\hline : & $\begin{array}{l}\text { Criar, produzir } \\
\text { e revisar textos } \\
\text { acadêmicos que } \\
\text { sejam: claros, } \\
\text { corteses, completos, } \\
\text { corretos: aceitáveis. }\end{array}$ & $\begin{array}{l}\text { Compor, revisar e editar } \\
\text { documentos em resposta } \\
\text { a estudos de casos que } \\
\text { sejam: informativos, bem } \\
\text { organizados, lógicos, } \\
\text { persuasivos. }\end{array}$ & $\begin{array}{l}\text { Selecionar estratégias } \\
\text { retóricas apropriadas } \\
\text { para persuadir } \\
\text { públicos diversos a } \\
\text { aceitar conclusões. }\end{array}$ \\
\hline 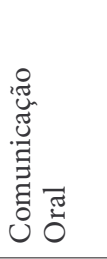 & $\begin{array}{l}\text { Expor uma } \\
\text { apresentação breve } \\
\text { e informal. }\end{array}$ & $\begin{array}{l}\text { Desenvolver e expor uma } \\
\text { apresentação acadêmica } \\
\text { formal que seja: } \\
\text { articulada, inteligível, } \\
\text { ensaiada, organizada, } \\
\text { dinâmica, visualmente } \\
\text { interessante }\end{array}$ & $\begin{array}{l}\text { Criar e apresentar } \\
\text { uma apresentação } \\
\text { acadêmica e } \\
\text { moderar discussões } \\
\text { com utilização de } \\
\text { recursos retóricos } \\
\text { apropriados. }\end{array}$ \\
\hline 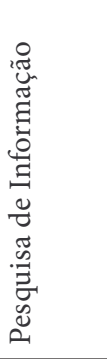 & $\begin{array}{l}\text { Escrever textos que } \\
\text { contenham resumo } \\
\text { e documentação de } \\
\text { informação obtida } \\
\text { de várias fontes }\end{array}$ & $\begin{array}{l}\text { Escrever recomendação } \\
\text { que selecione, analise } \\
\text { e organize informação } \\
\text { recolhida de fontes } \\
\text { múltiplas, inclusive } \\
\text { fontes eletrônicas }\end{array}$ & $\begin{array}{l}\text { Escrever textos } \\
\text { analíticos refinando } \\
\text { determinado } \\
\text { tópico: seleção, } \\
\text { avaliação, síntese e } \\
\text { documentação de } \\
\text { informação complexa } \\
\text { de várias fontes, com } \\
\text { inclusão de artigos } \\
\text { acadêmicos }\end{array}$ \\
\hline
\end{tabular}


Tabela 2 - Competências filosóficas

\begin{tabular}{|c|c|c|c|}
\hline $\begin{array}{l}\text { compe- } \\
\text { tência }\end{array}$ & básico & intermediário & avançado \\
\hline 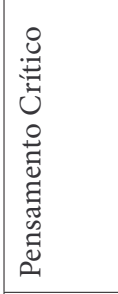 & $\begin{array}{l}\text { Identificar elementos- } \\
\text { chave em pesquisas } \\
\text { acadêmicas } \\
\text { informadas } \\
\text { concisamente. }\end{array}$ & $\begin{array}{l}\text { Definir um problema, } \\
\text { formular os objetivos, } \\
\text { propor e analisar } \\
\text { soluções razoáveis e } \\
\text { fazer recomendações } \\
\text { sobre casos. }\end{array}$ & $\begin{array}{l}\text { Avaliar situações } \\
\text { da elaboração de } \\
\text { textos em termos de } \\
\text { forças e fraquezas do } \\
\text { argumento, ameaças } \\
\text { e oportunidades } \\
\text { dos contextos/casos } \\
\text { escolhidos para estudo }\end{array}$ \\
\hline 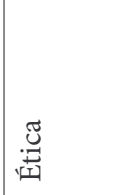 & $\begin{array}{l}\text { Usar linguagem direta, } \\
\text { evitar exageros e } \\
\text { falácias lógicas e saber } \\
\text { reconhecer práticas } \\
\text { não-éticas. }\end{array}$ & $\begin{array}{l}\text { Saber escolher } \\
\text { soluções apropriadas } \\
\text { a dilemas éticos que } \\
\text { envolvam várias partes } \\
\text { interessadas. }\end{array}$ & $\begin{array}{l}\text { Aplicar princípios } \\
\text { de ética acadêmica a } \\
\text { decisões. }\end{array}$ \\
\hline 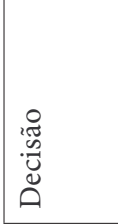 & $\begin{array}{l}\text { Identificar } \\
\text { causa e efeito de } \\
\text { decisões sobre } \\
\text { encaminhamento de } \\
\text { textos simples. }\end{array}$ & $\begin{array}{l}\text { Usar argumentos } \\
\text { de fato, políticas } \\
\text { acadêmicas e valores. }\end{array}$ & $\begin{array}{l}\text { Aplicar conjuntos } \\
\text { explícitos de critérios } \\
\text { para avaliar os } \\
\text { problemas de pesquisa } \\
\text { e encontrar a melhor } \\
\text { solução. }\end{array}$ \\
\hline 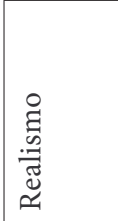 & $\begin{array}{l}\text { Aplicar somente } \\
\text { conhecimentos } \\
\text { relevantes. }\end{array}$ & $\begin{array}{l}\text { Determinar como } \\
\text { fatores éticos, globais, } \\
\text { políticos, tecnológicos } \\
\text { e culturais afetam o } \\
\text { desenvolvimento do } \\
\text { texto e as conclusões. }\end{array}$ & $\begin{array}{l}\text { Definir, avaliar e } \\
\text { resolver problemas } \\
\text { de comunicação que } \\
\text { afetam o texto. }\end{array}$ \\
\hline
\end{tabular}

Fonte: a autora (adaptado de Brzovic et all., 2006)

\section{Sociorretórica}

A sociorretórica ocupa-se da comunicação e das estruturas retóricas, mas de que forma isso se manifesta? Sem se desligar completamente dos conceitos aristotélicos, Bazerman (2013, p. 22) escreveu que "A retórica também difere das outras artes da língua porque adota o ponto de vista dos usuários, em vez da posição não comprometida do analista do código". Tal postura privilegia a capacidade de comunicação efetiva, centrada no auditório (PERELMAN, 1999) e detalhada nas Tabelas 1 e 2 adaptadas de Brzovic et all. (2006), que favorecem a construção de argumentos. Ao lembrar que “(...) a retórica constrói-se para a ação, em vez de para a des- 
crição estática" (BAZERMAN, 2013, p. 13) e que "as questões fundamentais da retórica têm a ver com maneiras de realizar coisas, e não com o que as coisas são" (idem) o autor reforça o caráter sociorretórico que, a nosso ver, pode ser aplicado aos textos acadêmicos, ou seja, "definir, avaliar e resolver problemas de comunicação que afetam o texto" (ibidem) (Tabela 2).

Podemos dizer que tanto as competências formais avançadas da Tabela 1 quanto as filosóficas avançadas da Tabela 2 estão centradas em Bazerman, quando afirma que "(...) Vale a pena saber como funciona a língua em contexto, porque isso permite saber como usá-la. (...) localizar-se na atividade, a definir seus interesses e a reconhecer e mobilizar recursos para a interação" (BAZERMAN, 2013, p. 22).

Swales (1990), para quem o entendimento dos objetivos da comunicação é central ao tratamento sociorretórico, influenciou o pensamento de Bhatia (1993), que justifica o estudo do gênero como entendimento do propósito comunicativo. Assim, o autor define e comenta gênero como:

uma instância de sucesso em um propósito comunicativo específico com utilização do conhecimento de recursos linguísticos e discursivos adaptados para o convencional. Como cada gênero, em certos aspectos importantes, estrutura o mundo estreito da experiência ou realidade de um modo particular, está implicado que a mesma experiência ou realidade irá requerer um modo diferente de estruturação ao se operar em um gênero diferente. (BATHIA, 1993, p. 116) (tradução da autora).

O gênero artigo acadêmico se enquadra nas observações de Swales (1990), Bhatia (1993) e, ainda, no que diz Bazerman (2013):

os gêneros emolduram e situam o momento da escrita, mas não a obscurecem em generalidades. Os gêneros, poderíamos dizer, identificam um espaço e um evento e implicam algumas orientações, compreensões típicas instrumentos e trajetórias possíveis, mas não nos dizem exatamente como o evento vai se desenvolver. (BAZERMAN, 2013, p. 45).

Em outras palavras, o artigo estabelece um momento na escrita, identifica um espaço, implica em orientações e trajetórias plausíveis. É possível, muitas vezes, que o gênero escolhido neste trabalho (artigo acadêmico) tome caminhos diversos daqueles definidos inicialmente, por isso, ainda conforme Bazerman (2013, p. 45), "haverá demasiadas coisas envolvidas 
para conseguirmos ver claramente para onde todas as nossas compreensões, pensamentos e impulsos nos levam".

Embora Toulmin (2013) não esteja especificamente ligado à sociorretórica e não tenha trabalhado estritamente com gêneros textuais, seu método de análise estrutura o argumento de modo a nos levar a crer na possibilidade de integração ao corpo de conhecimento da sociorretórica, uma vez que a maneira como está constituído seu método conduz a uma comunicação mais eficaz. $\mathrm{O}$ artigo acadêmico implica em desenvolvimento estruturado de argumentos da mesma forma que a sociorretórica.

\section{Solidez do argumento e sociorretórica}

Toulmin (2013) desenvolveu um modelo denominado layout do argumento. De acordo com autor, o argumento possui seis componentes, representados no esquema da Figura 1. Os seis elementos se relacionam de diversos modos, embora a identificação de cada um deles seja feita por meio da função que cada um exerce. O diagrama mostrado permite a análise da interrelação de microargumentos e subargumentos que compõem uma estrutura maior. Para facilitar a compreensão, o esquema inclui um exemplo.

Figura 1: Modelo argumentativo de Toulmin

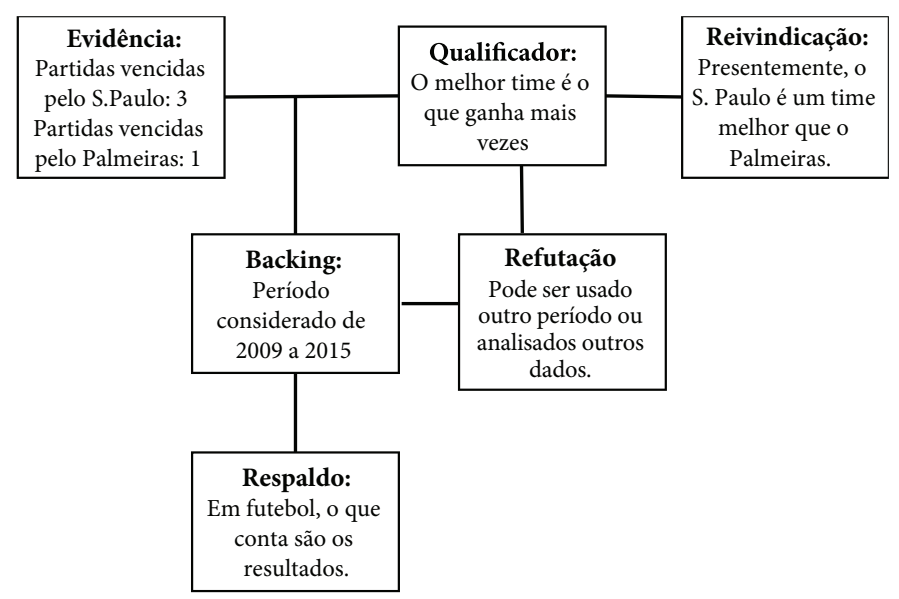

Fonte: a autora. 
Um argumento assim elaborado se desdobra e revela os pontos fortes e limites: nenhuma alegação deve ser mais forte do que o necessário nem ir além de sua própria pretensão. A questão, segundo Toulmin (2013), não é ganhar ou perder os contra-argumentos, mas chegar o mais próximo da verdade ou o mais perto de uma solução realista ou possível. Tal afirmação pode funcionar como elemento tranquilizador, uma vez que retira do orador ou produtor do texto a obrigação de ganhar a questão a qualquer custo.

Assim, responder a um argumento ou compreendê-lo vai muito além de concordar ou discordar dele: é determinar a base do acordo ou desacordo. Em outras palavras, analisar um argumento passa a ser um processo de descoberta de como as estratégias argumentativas são trabalhadas, de que maneira e por quais níveis elas transitam e nos conduzem a responder aos conteúdos a que somos expostos. Algumas vezes, tais análises podem modificar nossa compreensão ou julgamento e fazer com que nossos argumentos sejam afetados. A sociorretórica, conforme comentado, prevê mudanças de rota (BAZERMAN, 2013).

O método de Toulmin (2013) pode se tornar, assim, maneira efetiva de mostrar a maneira e em que níveis alcançamos os argumentos ou somos por eles afetados. É uma forma de análise que permite dividir um argumento em diferentes elementos. Essa anatomia, esse estudo, permite entender o argumento mais profundamente, sumarizando-o. Possibilita ainda discutir ou verificar sua eficácia ou ineficiência. A sociorretórica prevê a comunicação efetiva, o que implica no que foi sugerido por Toulmin (2013).

As partes do argumento, de acordo com esse autor, são: pretensão, reivindicação, razões, evidência, antecipação, objeções e refutação.

1. Pretensão/conclusão (claim): são fatos ou evidências utilizadas para comprovar o argumento; proposição que defende, sustenta, afirma, nega ou solicita algo. Trata-se do objetivo do argumento, o que se tenta provar, a tese. O primeiro passo para analisar e criticar o argumento é entender, com segurança, onde se quer chegar (Toulmin, 2013). Como exemplo, podemos pensar a definição do objetivo do artigo. Esse é o argumento que se deve provar válido.

2. Razões/dados (grounds/data): trata-se da proposição em processo de discussão. São os fatos ou dados que sustentam a conclusão. Em outras palavras, são os motivos, as evidências, as causas ou circunstâncias que apoiam a conclusão, que justificam a tese. Considera-se, nessa etapa, qual tipo de razão será necessária para que a conclusão se torne aceita como confiável (Toulmin, 2013). No caso da produção de um artigo, podem ser citadas as entrevistas, o estudo de campo, os questionários. 
3. Garantia (warrant): nessa etapa estão as declarações lógicas gerais, hipotéticas e, muitas vezes, implícitas que servem de ponte entre as pretensões e os dados. A garantia estabelece um vínculo entre a conclusão e as razões (pode ser uma fórmula, uma regra formal, a interpretação de um princípio). É importante verificar se as razões realmente fornecem um apoio para a conclusão e não se tratam apenas de informações irrelevantes que nada têm a ver com a conclusão levantada (Toulmin, 2013). Isso significa, na estruturação de artigos, a existência de uma lógica argumentativa entre os dados obtidos na pesquisa de campo e a teoria escolhida para fundamentar aquele texto, ou seja, a coerência entre as respostas dos entrevistados e a proposição do trabalho.

4. Respaldo (backing): são declarações que limitam a força do argumento ou que propõem as condições sob as quais o argumento é verdadeiro; o fundamento que valida ou dá suporte à garantia: fundamento sólido, material; aquilo que, em regra, não é alvo de questionamento. Além das razões que fundamentam determinado argumento, Toulmin (2013) diz que "é preciso descobrir a fonte genérica de informações". Na elaboração de artigos, o respaldo seria o uso de metodologia comprovada e, por exemplo, a qualificação dos entrevistados.

5. Qualificador (qualifier): não se trata, necessariamente, de provas que reforçam o argumento principal. Podem ser contra-argumentos ou declarações que indicam as circunstâncias em que o argumento geral não seja verdadeiro. Sempre que aparecem são mostrados por meio de advérbios ou adjetivos, que definem a força da conclusão, comumente expressa por meio de termos como necessariamente ou possivelmente. Qualquer conclusão é apresentada com certa força ou fraqueza, condições ou limitações (Toulmin, 2013). No exemplo, pode-se afirmar que o esforço não será válido e não terá resultados se o artigo não for devidamente planejado, pois corre o risco de se transformar em um texto sem direcionamento. Nesse caso, pode aparecer, na conclusão ou nos resultados, o advérbio possivelmente, que limita a força do argumento.

6. Refutação (rebuttal): são afirmações que podem reduzir ou anular a força do argumento, marcada por ressalvas, restrições, anuladores, ou seja, uma hipótese em que o argumento principal não se sustente. Toulmin (2013) afirma que se trata de circunstâncias extraordinárias ou excepcionais que chegam a comprometer a alegação. Uma refutação ao argumento da utilidade da escrita de artigo seria qualquer contra-argumento a essa utilidade. Uma forma de anular a refutação seria antecipá-la e responder, no próprio texto, para garantir a solidez do argumento. 


\section{Estudo de caso: elaboração de artigo por alunos}

Este trabalho tomou como exemplo o ensino de artigos acadêmicos para alunos de primeiro semestre das disciplinas de Leitura e Produção de Texto e Métodos da Produção do Conhecimento. Conforme comentado, a pesquisa tem sido feita durante seis anos a um total de aproximadamente 800 alunos.

\section{Uso da metodologia como estímulo}

A fim de enfrentar o problema da falta de motivação, uma das várias abordagens tentadas tem produzido resultados significativamente positivos. A metodologia pode ser resumida em dois pontos estritamente ligados à sociorretórica: 1) basear cada trabalho em pesquisa percebida como relevante - desenvolvimento de artigo com tema de interesse do aluno e 2) garantir que os estudantes desempenhem um papel ativo, com suas próprias decisões sobre os caminhos e métodos de pesquisa, sem esquecer a preocupação com um monitoramento cuidadoso e uma instrução detalhada. Ainda em obediência aos princípios sociorretóricos, a estrutura retórica é garantida pelo uso do layout do argumento de Toulmin (2013).

O desenvolvimento de artigos acadêmicos nas escolas tecnológicas selecionadas tem sido solicitado a estudantes de duas disciplinas: uma especializada em escrita: Leitura e Produção de Textos, e outra em pesquisa: Método da Produção do Conhecimento. Há uma coordenação centralizada de trabalhos acadêmicos para auxiliar os professores, uma vez que a atividade é essencialmente multidisciplinar e envolve, ao mesmo tempo, pesquisa e escrita.

Os alunos recebem uma lista de temas que sejam significativos a eles e que tenham relação estreita com o curso, no caso, Tecnólogo em Gestão ${ }^{4}$. Por exemplo, se um estudante está particularmente interessado em esportes, um tema típico seria a viabilidade de organizar um torneio de futebol amador entre algumas cidades vizinhas. Os temas são selecionados pelos grupos de alunos, em número de, no máximo, três. A estudantes que se interessam por cultura, pode ser apresentado, como tema, a influência 
da cultura local nos eventos. Existem dois tipos de motivação: a própria curiosidade, induzida pelo tema escolhido, e a preparação para a vida profissional, objeto de conversas de incentivo planejadas, para mostrar como tal esforço é importante para alcançar o mercado de trabalho com maior preparo.

O plágio tem sido abordado em duas linhas: a investigação e a discussão. Cada parágrafo produzido pelos alunos é verificado por meio de, pelo menos, dois softwares de investigação de plágio que, quando encontrado, é exposto. Além disso, aulas específicas sobre ética são ministradas, com incentivo a discussões sobre o caráter de fraude do plágio.

No início do esforço, se ministrava uma aula de ética, que rapidamente evoluiu para duas, graças ao interesse dos estudantes no tema. As questões éticas são abordadas à luz do utilitarismo e do imperativo categórico (SANDEL, 2009), e a falta de qualquer possibilidade de defesa para o plágio é exaustivamente demonstrada.

\section{Aulas teóricas e entregas intermediárias}

São ministradas aulas teóricas sobre metodologia científica e retórica, ambas as disciplinas pelo mesmo professor. Um curso rápido (crash course) sobre metodologia de estudo de caso é efetuado após a atribuição dos temas, para que os estudantes entendam os fundamentos do método, conforme Robert Yin ${ }^{5}$ (2013). As etapas da pesquisa estão listadas a seguir, juntamente com as atividades correspondentes solicitadas aos estudantes. Tais fases estão associadas à sociorretórica, conforme mostrado em parágrafos anteriores, embora de maneira indireta. $\mathrm{O}$ artigo é construído e entregue em várias etapas.

Questões de estudo, também chamadas de questões de pesquisa, são as perguntas que o aluno elabora a si mesmo, com a intenção de nortear a investigação. Exemplos de questões são: por quê, como, qual a maneira? Tais perguntas são analisadas pelo professor e discutidas com os alunos ou grupos. A clareza dessas questões está diretamente relacionada à excelência da comunicação com o leitor, um cânon da sociorretórica.

As equipes, após escolher os temas, decidem sobre tais questões e con-

5 Robert Yin é teórico norteamericano que elaborou metodologias para o desenvolvimento de trabalhos acadêmicos, neste capítulo focado no estudo de caso 
cebem um programa de investigação histórica, entrevistas com cidadãos, líderes empresariais ou políticos, locais ou representantes de outros espaços considerados significativos, além do recolhimento de informações junto a indivíduos com conhecimento relevante para a pesquisa.

Proposições de estudo: não se trata exatamente do que o pesquisador quer saber, mas daquilo que ele está tentando alcançar. É comum que os estudantes apresentem dificuldade em compreender a diferença entre questões de estudo e proposições, essas últimas equivalentes aos objetivos de um trabalho acadêmico. Uma boa forma de superar tais dificuldades é a utilização da maiêutica (método socrático), ou seja, por meio de perguntas, os alunos são instados a explicar sobre o que pretendem realizar com sua pesquisa ou, em outras palavras, onde desejam chegar.

Unidade de análise e dados: a definição da unidade de análise tem se revelado importante, uma vez que os estudantes apresentaram forte tendência a perder o foco. Nessa fase, eles definem o que exatamente irão pesquisar: o local, um evento específico, um fato, um caso definido.

Lógica que liga os dados às proposições: uma forma de ensinar esse passo é por meio de uma pergunta simples: o que se vai fazer com os dados coletados? Trata-se de etapa importante na estruturação e organização da pesquisa e, apesar da simplicidade da questão sobre o que fazer com os dados, é conveniente que o momento seja acompanhado pelo professor.

Nesse momento o professor pode apresentar uma lista de referências, livros, artigos acadêmicos, revistas, ciberespaços confiáveis sobre o tema. Os alunos são incentivados a efetuar leituras antes da entrega, que consiste na descrição da unidade de análise e o detalhamento da lógica de vinculação de dados com as proposições. A experiência tem mostrado que, quando a fundamentação teórica é solicitada antes dessa fase, os estudantes apresentam maior tendência a efetuar colagem de textos e acham que o trabalho está finalizado.

Após a avaliação dessa entrega ${ }^{6}$, cada equipe é convidada a apresentar um protocolo de pesquisa, que compreende tema, questões, proposições, dados a serem obtidos e uma descrição de como os dados serão organizados para realizar as proposições. A relevância de saber colocar por escrito a conexão entre dados e proposições é bastante enfatizada, por ser necessária para a comunicação priorizada pela sociorretórica.

6 Conforme mencionado, existem entregas intermediárias, a primeira delas com as questões de pesquisa, proposições, unidade de análise e dados. 
Pesquisa de Campo: consiste no levantamento efetivo dos dados por meio de 1) questionários previamente elaborados e corrigidos a serem entregues a populações determinadas e/ou 2) roteiros de entrevistas com indivíduos conhecedores de aspectos da pesquisa.

\section{O trabalho final}

Em meio à construção das etapas, os alunos recebem instrução formal sobre a estruturação e formatação de um trabalho acadêmico: como escrever resumo, introdução, bibliografia, fundamentação teórica, normas sobre citações diretas e indiretas.

A entrega seguinte é uma versão quase finalizada do artigo já formatado. Mesmo após instrução prévia, é possível haver alguma dificuldade em diferenciar introdução, conclusões e resumo. Eles recebem os projetos anotados e produzem novas versões até que o texto esteja considerado pronto. Geralmente, o trabalho é finalizado após a segunda ou terceira revisão. Tais atividades auxiliam a desenvolver qualidades que irão ajudá-los profissionalmente: organização do pensamento, apresentação deles de forma concisa, entendimento do que são chamados a realizar e concentração em tarefas específicas, características que atendem aos princípios da sociorretórica e suas implicações, mostradas, em parte, nas Tabelas 1 e 2, no início deste capítulo, nomeadas como Competências Formais e Filosóficas.

\section{Exemplo de artigo produzido por alunos de primeiro semestre}

O trabalho aqui tomado para exemplificar teve como tema encontrar a ação mais eficaz para auxiliar uma cidade na área onde a Fatec está localizada a se tornar um polo logístico e, dessa maneira, atrair empresas e gerar empregos. A cidade foi espaço de um entroncamento ferroviário histórico importante entre os anos 1890 e meados dos anos 1960, e tem experimentado alguma decadência após a extinção da linha ferroviária. Ainda está bem localizada, a meio caminho entre Rio de Janeiro e São Paulo, e abriga áreas complementares em produção e consumo. A Tabela 3 mostra, resumidamente, as aproximações metodológicas, retóricas e sociorretóricas que se pode verificar na confecção de um artigo. 
Tabela 3: Relação entre metodologia de desenvolvimento, sociorretórica e análise do argumento

\begin{tabular}{|c|c|c|c|}
\hline Artigo escolhido & Yin & Toulmin & Sociorretórica \\
\hline $\begin{array}{l}\text { Verificação das } \\
\text { possibilidades de } \\
\text { uma cidade do } \\
\text { Vale do Paraíba } \\
\text { restabelecer } \\
\text { proeminência como } \\
\text { centro logístico }\end{array}$ & Tema & Início do argumento & $\begin{array}{l}\text { Desenvolvimento da } \\
\text { capacidade de elaboração } \\
\text { do pensamento }\end{array}$ \\
\hline $\begin{array}{l}\text { A história da cidade } \\
\text { leva a crer que seja } \\
\text { um polo logístico? } \\
\text { A cidade é ou pode } \\
\text { ser alavancada como } \\
\text { centro logístico na } \\
\text { região }\end{array}$ & $\begin{array}{l}\text { Questões de } \\
\text { Pesquisa }\end{array}$ & $\begin{array}{l}\text { Orientação da } \\
\text { coleta de dados para } \\
\text { backing, evidência } \\
\text { e argumentação } \\
\text { presente na } \\
\text { conclusão }\end{array}$ & $\begin{array}{l}\text { Capacidade de análise do } \\
\text { tema para elaboração do } \\
\text { pensamento complexo } \\
\text { e desenvolvimento da } \\
\text { argumentação }\end{array}$ \\
\hline $\begin{array}{l}\text { Verificação dos } \\
\text { setores mais } \\
\text { representativos } \\
\text { economicamente } \\
\text { e que poderiam } \\
\text { contribuir para a } \\
\text { criação de um polo } \\
\text { logístico }\end{array}$ & Proposição & $\begin{array}{l}\text { Orientação da } \\
\text { reivindicação }\end{array}$ & $\begin{array}{l}\text { Desenvolvimento } \\
\text { de pensamento } \\
\text { argumentativo voltado } \\
\text { para a comunicação e de } \\
\text { competências filosóficas }\end{array}$ \\
\hline $\begin{array}{l}\text { Cidade determinada } \\
\text { (não citação do nome } \\
\text { para evitar problemas } \\
\text { ligados à ética) }\end{array}$ & $\begin{array}{l}\text { Unidade de } \\
\text { Análise }\end{array}$ & Backing & $\begin{array}{l}\text { Capacidade de análise } \\
\text { retórica e de competências } \\
\text { para escolha de local } \\
\text { apropriado para análise }\end{array}$ \\
\hline $\begin{array}{l}\text { Respostas a } \\
\text { questionários com } \\
\text { perguntas fechadas } \\
\text { a profissionais do } \\
\text { ramo logístico da } \\
\text { cidade escolhida e } \\
\text { entrevistas }\end{array}$ & Dados & Evidência e backing & $\begin{array}{l}\text { Desenvolvimento da } \\
\text { capacidade argumentativa } \\
\text { (na comunicação oral e } \\
\text { escrita) para formulação e } \\
\text { aplicação do questionário } \\
\text { e entrevistas }\end{array}$ \\
\hline $\begin{array}{l}\text { Escolha de assuntos } \\
\text { pertinentes e autores } \\
\text { confiáveis }\end{array}$ & $\begin{array}{l}\text { Fundamenta- } \\
\text { ção Teórica }\end{array}$ & Evidência e respaldo & $\begin{array}{l}\text { Capacidade de escolha e } \\
\text { de desenvolvimento da } \\
\text { estrutura retórica a ser } \\
\text { utilizada }\end{array}$ \\
\hline $\begin{array}{l}\text { Resultados e } \\
\text { Conclusões }\end{array}$ & $\begin{array}{l}\text { Análise dos } \\
\text { dados }\end{array}$ & $\begin{array}{l}\text { A pretensão está } \\
\text { nos resultados; o } \\
\text { qualificador está na } \\
\text { argumentação que } \\
\text { suporta os resultados, } \\
\text { que devem conter } \\
\text { argumentos que } \\
\text { refutem uma possível } \\
\text { objeção (refutação) }\end{array}$ & $\begin{array}{l}\text { Desenvolvimento da } \\
\text { capacidade argumentativa } \\
\text { e das competências } \\
\text { avançadas de comunicação } \\
\text { escrita }\end{array}$ \\
\hline
\end{tabular}

Fonte: a autora. 


\section{Resultados}

Os resultados têm sido, em geral, gratificantes para alunos e professores. Um questionário curto foi aplicado a 480 alunos após a conclusão e apresentação de seus trabalhos. As respostas estão na Tabela 4 a seguir.

Tabela 4 - Resultado da pesquisa de satisfação dos alunos

\begin{tabular}{|l|l|l|l|l|l|}
\hline & $\begin{array}{l}\text { concorda } \\
\text { fortemente }\end{array}$ & concorda & $\begin{array}{l}\text { não concorda } \\
\text { nem discorda }\end{array}$ & discorda & $\begin{array}{l}\text { discorda } \\
\text { fortemente }\end{array}$ \\
\hline $\begin{array}{l}\text { Tive prazer em } \\
\text { escrever o artigo }\end{array}$ & $32 \%$ & $22 \%$ & $22 \%$ & $10 \%$ & $14 \%$ \\
\hline Fui bem orientado & $48 \%$ & $28 \%$ & $5 \%$ & $10 \%$ & $9 \%$ \\
\hline Aprendi muito & $51 \%$ & $18 \%$ & $12 \%$ & $10 \%$ & $9 \%$ \\
\hline
\end{tabular}

Fonte: a autora.

Conforme verificado na Tabela 4, a maioria dos alunos demonstrou ter prazer na atividade (54\%), ou seja, concordam fortemente ou concordam; $76 \%$ consideram ter sido bem orientados e $79 \%$ concordaram ter aprendido bastante.

Um questionário que permitia respostas múltiplas foi encaminhado a 73 professores e as respostas se encontram na Figura 2, a seguir.

Figura 2: Benefícios do ensino da produção de artigos acadêmicos no $1^{\circ}$ semestre de cursos de nível superior

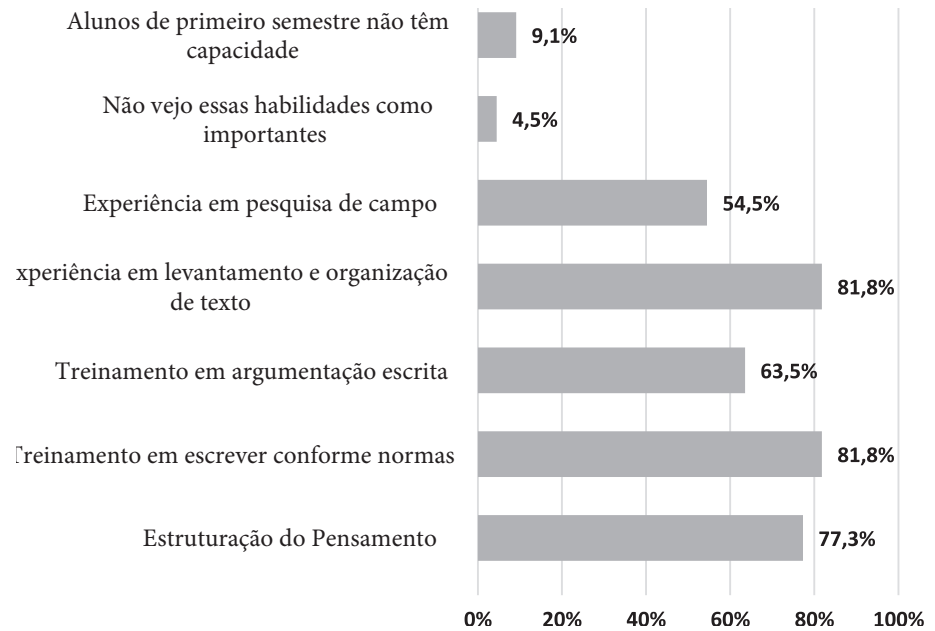

Fonte: a autora. 
Conforme se observa, os professores concordam, em sua maioria, com a necessidade e importância do ensino do artigo já a partir do primeiro semestre nos cursos superiores. As porcentagens mostram que essa produção acadêmica pode auxiliar na estruturação do pensamento, permite o treinamento do estudante no uso da argumentação e trabalha a organização textual, três princípios da sociorretórica apontados por Swales (2004). Bazerman (2013) reforça que a retórica, diferentemente das outras artes da língua, adota o ponto de vista dos usuários, em vez da posição não comprometida do analista. Tal postura privilegia a capacidade de comunicação efetiva, centrada, o que realmente ocorre na produção do artigo acadêmico, conforme se pode perceber no estudo de caso e na Tabela 3.

Apenas 4,5\% não percebem tais habilidades como importantes e 9,1\% consideram que os alunos de primeiro semestre não têm capacidade para a produção de textos dessa natureza. Nas respostas livres, $1 \%$ considera mais importante o nivelamento de Português e Matemática, $1 \%$ respondeu que tais habilidades promovem contato com a linguagem acadêmica, o que reforça os itens anteriores e um professor afirmou que se trata do "ingresso no mundo científico do qual nenhuma instituição superior deveria abrir mão, pois dele depende o progresso do país".

\section{Considerações finais}

A produção de trabalhos acadêmicos tem sido acompanhada, conforme mencionado, por seis anos (doze semestres), e percebe-se que a metodologia evoluiu no período. Com o tempo, o número de entregas durante o desenvolvimento de cada artigo aumentou. Cerca de metade dos alunos passou a considerar o artigo acadêmico de maneira mais séria. Para parte deles ainda se configura, principalmente, como um obstáculo a ser vencido, porém esse número tem se reduzido.

O plágio, até certo ponto, continua uma dificuldade a ser combatida por meio de convencimento durante as aulas de Métodos da Produção do Conhecimento e nas orientações efetuadas junto aos grupos. Embora a investigação e escrita acadêmica tenham se mostrado eficazes, o plágio, infelizmente, parece se manter, talvez como consequência de algum tipo de cultura. Não ocorre apenas com alunos de primeiro semestre: apesar das informações e cobranças, os estudantes mantêm esse costume, mesmo após muito debate. Para combatê-lo, o plágio tem sido exposto e é fornecido 
novo prazo para que os alunos reformulem seus textos em caso de cópia.

Conforme verificado, a orientação está concentrada na elaboração de questões de pesquisa e determinação dos dados, avaliação e debate do protocolo de pesquisa, revisão dos rascunhos e preparação da versão final. Todas essas instâncias, somadas à determinação de uma pesquisa de campo, elaboração de questionários, entrevistas e a própria produção do texto reforçam o caráter sociorretórico da escrita acadêmica, tendo em vista que se trata da elaboração de argumentos voltados à comunicação de temas escolhidos.

Embora não seja possível medir a melhora nas redações, considerando que se trata de resultados intangíveis, percebe-se que o aperfeiçoamento textual evolui naturalmente com a maturidade, desenvolvida ao longo dos semestres. Além dos resultados da pesquisa entre alunos e professores que nos leva a acreditar que a escrita acadêmica aperfeiçoa a capacidade de produzir documentos em geral, uma das indicações de progresso reside justamente no desempenho escrito e oral observado entre os professores e pelos próprios alunos em comentários informais. Docentes demonstram satisfação com textos de seus alunos após os semestres de treinamento e os próprios estudantes percebem o progresso no desenvolvimento de textos e maior facilidade de comunicação oral após as apresentações.

Por outro lado, alguns estudantes nem sempre gostam desse trabalho, que é cansativo, com muitas repetições, correções, das cobranças e do esforço, mas os professores de todos os departamentos têm manifestado entusiasmo com a produção de artigos acadêmicos, conforme verificado por meio da pesquisa cujos resultados são mostrados na Figura 2, ou seja, o desenvolvimento de uma investigação e produção de artigos acadêmicos propicia amadurecimento intelectual e na comunicação, conforme preconiza a sociorretórica.

A ideia de utilizar o layout de Toulmin (2003) para verificar a integridade e consistência dos argumentos pode ser aplicada, principalmente, na finalização do artigo.

Em outras palavras, acreditamos que o emprego da sociorretórica conforme Swales (2004) e Bazerman (2015), o uso da metodologia de Yin e uma verificação argumentativa do artigo, conforme Toumin (2003), proporcionam confiabilidade e consistência ao trabalho e suas conclusões. 


\section{Referências}

ARISTÓTELES. Arte Retórica e Arte Poética. Trad. AB Cavalho, 14 ed. Rio de Janeiro, Ediouro, 2003 (trabalho original publicado em cerca de 320aC).

BAKHTIN, M. Estética da Criação Verbal. São Paulo: Martins Fontes, 2006.

BAZERMAN. C. Retórica da ação letrada. Trad. Adail Sobral et all. São Paulo: Parábola Editorial, 2015.

BHATIA, V. K. Analysing Genre: Language Use in Professional Settings. New York: Longman, 1993.

BRZOVIC, K., et all. Core Competencies and Assessment in Business Writing. University of California, Fullerton, 2006.

CASTELLÓ, M. El proceso de composición de textos académicos. In: CASTELLÓ, M. (Coord.) Escribir y comunicarse en contextos científicos y académicos. Barcelona: GRAÓ, 2010.

FAIRCLOUGH, N. Discurso e mudança social. Trad. Maria Izabel Magalhães. Brasília: UnB, 2001.

HALLIDAY, M. An introduction to functional grammar. London: Edward Arnold, 1994.

MAINGUENEAU, D. Novas Tendências em Análise do Discurso. 3 ed. Campinas: Pontes Editora da Universidade Estadual de Campinas, 1997.

MEYER, M. A Retórica. 1 ed. Portugal: ASA, 1997.

O'HARA, C. Article November 20. Disponível em https://hbr.org/2014/11/ how-to-improve-your-businesswriting

PERELMAN, C. e TYTECA, L. O. Tratado da Argumentação - A Nova Retórica. São Paulo: Martins Fontes. 1999, (Trabalho original publicado em 1958).

SANDEL, M.: What's the Right Thing to Do? New York: Farrar, Straus and Giroux, 2009.

SWALES, J. M. Research genres: explorations and applications. New York: Cambridge University Press, 2004.

TOULMIN, S. The Uses of Argument. Cambridge University Press, 2003. (Trabalho original publicado em 1958).

YIN, R. Case study research: design and methods. Thousand Oaks: Sage. 2013, (Trabalho original publicado em 1984) 

